\title{
Retrieving organs from non-heart-beating organ donors: a review of medical and ethical issues
}

\author{
[Prélèvement d'organes chez des donneurs à cour non battant : une revue éthique
} et médicale]

Christopher James Doig MD MSc, ${ }^{*}$ Graeme Rocker DM MHSc $\dagger$

Purpose: The increasing gap between numbers of individuals awaiting organ replacement surgery and the supply of organs available for transplant underpins attempts to increase the number of organs available. One practice, used in other countries, is the recovery of organs from non-heart-beating organ donors (NHBD). The purpose of this review is to discuss ethical issues surrounding the use of organs from these donors.

Source: Narrative review from selected Medline references, and other published reports.

Principal findings: NHBD protocols have been established in many countries including the United States. Despite numerous publications, and extensive debate in the literature, significant ethical issues remain unresolved in the retrieval of organs from donors that have died from cessation of cardiac activity. The ethical concerns primarily arise in the determination of death, the tension between the time constraints on recovering organs viable for transplantation, and procedures to enhance organ viability. Despite a concerted effort in the United States, less than half of the organ procurement organizations have NHBD protocols.

Conclusion: Canadian centres can learn from the difficulties encountered in other centres that have developed NHBD protocols. A moratorium on Canadian NHBD protocols should be considered until a National consensus reflecting Canadian values has been undertaken.

Objectif : L'écart croissant entre le nombre d'individus qui attendent une greffe d'organe et le nombre d'organes disponibles pour la transplantation soutient les tentatives d'augmenter le nombre d'organes disponibles. Dans certains pays, le prélèvement d'organes se fait chez des donneurs à cœur non battant (DCNB). L'objectif de la présente revue est de discuter des questions éthiques entourant cette pratique.
Source : La revue descriptive provient de références choisies dans Medline et d'autres articles publiés.

Constatations principales : Des protocoles de dons de DCNB ont été établis dans de nombreux pays, y compris les États-Unis. Malgré de nombreuses publications, et un intense débat dans la littérature scientifique, d'importantes questions d'éthique demeurent non résolues sur le retrait d'organes chez des donneurs morts à la suite de l'arrêt de l'activité cardiaque. Les préoccupations éthiques concernent principalement la détermination de la mort, la tension entre les contraintes de temps entourant le prélèvement d'organes viables pour la greffe et les techniques d'amélioration de la viabilité des organes. Malgré une mobilisation aux États-Unis, moins de la moitié des organisations de prélèvement d'organes ont établi des protocoles de DCNB.

Conclusion : Les centres canadiens peuvent apprendre à partir des difficultés rencontrées par d'autres centres qui ont mis au point des protocoles DCNB. Un moratoire sur les protocoles DCNB canadiens devrait être envisagé jusqu'à ce que soit établi un consensus national exprimant les valeurs canadiennes.

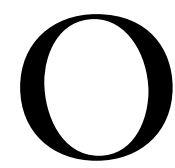

VER the past 30 years in North America, the primary source of organs obtained for transplantation has been from patients in whom a neurological determination of death has been made, (brain death). As the discipline of transplantation surgery has matured, the number of patients with end-organ failure eligible for organ replacement surgery has increased. Despite the growing 'demand' for organs, the number of potential (brain dead) donors and therefore the 'supply' of organs remains limited. ${ }^{1}$ In consequence, alternative sources of organs have been sought, including the

From the Department of Critical Care Medicine and The Office of Medical Bioethics, ${ }^{*}$ Faculty of Medicine, University of Calgary, Calgary, Alberta; and the Department of Medicine, $\dagger$ Dalhousie University, and The Intensive Care Program, Queen Elizabeth II Health Sciences Centre, Halifax, Nova Scotia, Canada. Address correspondence to: Dr. Christopher Doig, Department of Critical Care Medicine, Room EG23G, Foothills Medical Centre,

1403, 29th Street N.W., Calgary Alberta T2N 2T9, Canada. E-mail: cdoig@ucalgary.ca

Accepted for publication March 17, 2003.

Revision accepted September 3, 2003. 
retrieval from individuals declared dead by cardiopulmonary criteria i.e., when cardiac function ceases; known as a group as non-heart-beating donors $(\mathrm{NHBD})^{2,3}$ The rationale behind using NHBD includes: 1) the NHBD was the major source of organs for transplantation prior to the development and adoption of brain death criteria, ${ }^{4}$ and remains so in countries, e.g., Japan, where the concept of 'brain death' has only recently been adopted in legislation, but has yet to be widely accepted by the general populace, ;,6 2) the recovery of organs from NHBD does not violate the ethical principle of the 'dead donor' rule (see below); and 3 ) the determination of death by cardiopulmonary criteria is far more common; therefore, the pool of potential donors would include a larger group of patients, not only those patients dying from catastrophic brain injury. ${ }^{2,7}$ This article will review some of the medical and ethical issues surrounding the procurement of organs from NHBD.

\section{Changing epidemiology of brain death}

The success of organ donation and transplant programs is often based on estimates of the total number of donors per million population. Spain is credited with rates as high as 35 (brain dead) donors per million population. ${ }^{8}$ However, these rates do not adjust for the absolute incidence of brain death. In North America, the incidence of brain death is decreasing. The many reasons may include a decrease in the incidence of catastrophic brain injury, advances in the neurocritical care management of catastrophic brain injury (many patients no longer progress to brain death), and changes in the demographics of the general population. Baxter recently compared the potential number of brain dead donors in Canada vs Spain, and concluded that part of the lower rate of organ donation in Canada is due to Canadian public health initiatives that have reduced the incidence of severe traumatic brain injury as a consequence of motor vehicle accidents. ${ }^{9-11}$ Irrespective of the specific reason, the gap between organ demand and supply will continue to increase if organ retrieval only continues from donors that are brain dead, and in the absence of alternative strategies such as permitting organ retrieval from other sources such as NHBD.

\section{Classification of NHBD}

NHBD are usually classified based on the Maastricht criteria (Table I). ${ }^{12,13}$ A more practical classification may be "uncontrolled" or "controlled" NHBD depending on whether cardiopulmonary function ceases spontaneously or after medical therapy is withdrawn. For controlled NHBD (Maastricht category
TABLE I Maastricht categories for non-heart beating donors

Category I: dead on arrival

Category II: unsuccessful resuscitation

Category III: awaiting cardiac death

Category IV: cardiac death in a brain dead donor

III), the potential donor is identified after a decision has been made to withdraw life-sustaining medical therapy, and usually when the patient is in a critical care unit. Following the decision to withdraw treatment, the patient is assessed as an eligible potential donor and the family/patient are approached for consent. To avoid real or perceived conflict of interest, the health care team making the decision to withdraw lifesustaining medical therapy and the health care team responsible for the assessment of the patient as a potential donor are separate, and the decisions of each team are made independent of the other. If consent is obtained, the family says 'goodbye' in the intensive care unit (ICU), and the patient is transferred to the operating room. Cardiopulmonary support is then stopped. Following a predefined, but variable and centre specific, period of asystole, the patient is pronounced dead by a physician independent of the organ procurement team. The retrieval of organs proceeds immediately following this determination of death. For a more detailed description, the reader is referred to the protocol used at the University of Pittsburgh, ${ }^{14}$ and the recent reports by the Institute of Medicine. ${ }^{15,16}$ In some centres, ante-mortem interventions are used to minimize the consequence of warm ischemia during the period of withdrawal of treatment, declaration of death, and organ recovery. These interventions may include the ante-mortem administration of drugs such as heparin or phentolamine, or placement of vascular catheters used for in situ organ preservation. ${ }^{17}$ In situ organ preservation requires a catheter with proximal and distal occlusion balloons to be placed in the aorta. The balloons are inflated and preservative is instilled. At the same time, a foley catheter is placed in the inferior vena cava to drain the effluent. Usually, peritoneal trocars are also placed for instillation and recirculation of a refrigerated solution for local intra-abdominal cooling. Similar techniques for pleural cooling have also been described. ${ }^{18}$ The ethical implications of these approaches are discussed below.

Uncontrolled NHBD are usually patients in whom an attempt at resuscitation after a pre-hospital or in-hospital cardiac arrest has failed (Maastricht categories I and II). The minority of uncontrolled NHBD are patients iden- 
tified as brain dead, with consent for organ retrieval, but cardiac activity ceases prior to the start of organ recovery (Maastricht category IV). Retrieval of organs for transplant is more complex in uncontrolled donors as the interval between cessation of cardiac activity and organ retrieval is increased, and there is a greater risk of organ damage due to 'warm ischemia.' As such, time is limited in which to assess the potential donor, initiate discussions with family and allow them time to reflect and consent, before transporting the donor to the operating room. To increase this interval, some centres also use postmortem in situ organ preservation. There are data showing that in situ preservation can lengthen the period from one hour up to six hours between determination of death and organ recovery. ${ }^{19}$ However, in contrast to situations involving controlled donors, placement of these catheters and/or cooling may be performed without the consent of families; this is the standard practice in at least one organ procurement organization (OPO) NHBD protocol and similar approaches have been used at other centres. ${ }^{16,20}$ The ethical implications of this practice will be discussed below.

\section{Could NHBD make a difference to the organ shortage?}

Use of NHBD could contribute to an increase in the number of solid organs for transplantation including $20 \%$ or more to the supply of kidneys, and increasing the supply of other solid organs including liver, pancreas or pancreatic islet cells. ${ }^{21-27}$ Successful heart and lung transplants have been performed in animal models, and appear to be technically feasible. ${ }^{28-30}$ Recently, one centre has reported the retrieval and transplant of a lung from a controlled NHBD. ${ }^{18}$

A recent report from one Canadian centre estimated the potential number of NHBD by reviewing the deaths of 209 patients in the emergency department or ICU. ${ }^{31}$ Of the 209 deaths, 25 met NHBD criteria. A further two were deemed ineligible because of concomitant medical problems. Of the remaining 23, 17 met criteria as potential controlled NHBD and six as potential uncontrolled donors. Death occurred in 13 (72\%) of the 17 (potential controlled NHBD) patients within one hour, and in 16 (94\%) of patients within six hours of discontinuing medical therapy. During the same year, 33 potential organ donors met brain death criteria, of whom 21 (64\%) became donors. Family refusal was the primary impediment to organ recovery. The authors concluded that using an estimate of $25 \%$ refusal of consent, and a discard rate of $15 \%$ due to glomerulosclerosis, ten additional kidney donors could have been obtained.

A recent survey of the 63 OPO in the United States identified that 28 had approved protocols for organ retrieval from NHBD. ${ }^{16}$ The centre with the largest experience was the Gift of Life Donor program in Philadelphia; between 1995 and 1998, 71 cases or 6.5\% of all donors in their program were NHBD. The Washington Hospital Centre in Washington DC has reported that $30 \%$ of all their donors are $\mathrm{NHBD}$, but their centre permits in situ preservation without family consent. The success of other programs is more limited. Therefore, despite the perception of NHBD as a potentially large source of available organs, the success of established protocols has not been as dramatic as proponents of NHBD have suggested. ${ }^{32}$ Impediments to the establishment or success of NHBD protocols from this survey identified hospital factors such as unspecified lack of interest or resistance $(n=19)$, OPO factors $(n=$ 14) including limited resources or low priority, "organs" $(n=10)$ including an adequate local supply from heart-beating (brain dead) donors or poor organ quality from NHBD, adverse publicity $(n=9)$, and ethics otherwise unspecified $(n=6){ }^{16}$

In Canada, no centre reports use of $\mathrm{NHBD}$ as a source of solid organs for transplant.

\section{Ethical concerns with the use of NHBD}

The public and professional acceptance of organ recovery from donors, irrespective of whether they are heartbeating donors (brain dead) or NHBD is premised on two fundamental tenets: first observance of the 'deaddonor' rule, and second that the altruism of the gift of donation is not compromised by real or perceived conflict of interest within the health care team caring for the potential donor. ${ }^{33,34}$ The 'dead-donor' rule requires that a patient be considered as a potential donor only after the determination of death, ${ }^{35-37}$ and was part of the impetus for the seminal development of formal brain death criteria. ${ }^{38}$ Concerns over conflict of interest requires that the health care team responsible for declaring death and approaching families to ask for organ donation be distinct and separate from the health care team responsible for transplantation and management of potential recipients. These two ethical tenets ensure that, at all times, care to the potential donor is always in their best interests and that identification of a potential donor does not compromise either the determination of death, or treatment decisions prior to death. Within this ethical framework, the problems unique to NHBD are generated by concerns surrounding 'time and timing.' 39

\section{Time, timing and the determination of death}

With the need to reduce warm ischemia, organs must be recovered as quickly as possible after the cessation of cardiac activity. The simple question becomes: when in 
the course of ascertaining death, is the patient dead, and when can organs be taken? ${ }^{40}$ There is a tension between making certain organs are retrieved quickly (minimizing warm ischemic damage) and ensuring that the patient is in fact irreversibly dead when the surgical retrieval begins. ${ }^{40-42}$ Menikoff has criticized the definition of death in NHBD programs noting that cessation of cardiopulmonary activity is not irreversibly lost as long as it could conceivably be restored by vigorous resuscitation efforts. ${ }^{43}$ Cole has put forward the position that the term 'irreversible' may be interpreted variably depending on the context. For example, irreversible cessation of cardiac activity could mean: 1) will not resume spontaneously; or 2) cannot be restarted with resuscitation measures; or 3) will not be restarted on morally justifiable grounds. Supporters of NHBD protocols argue that since these donors undergo a deliberate withdrawal of life-sustaining therapy independent of the decision to recover organs, resuscitation is not an ethically appropriate intervention and should not be considered. ${ }^{41}$ Therefore, the only relevant condition to be determined is the likelihood of spontaneous resumption of cardiac activity. If a specified duration of absent cardiac activity is not associated with spontaneous 'auto-resuscitation,' then the absence of activity can be considered irreversible. The recent Institutes of Medicine report identified variability between centres in the duration of asystole required prior to organ retrieval (2-20 $\mathrm{min})$, and that limited research has been conducted on the likelihood of spontaneous 'auto-resuscitation. ${ }^{16}$ Their report recommended adoption of five minutes of observed cardiac asystole, with a caveat that further research is required to confirm that auto-resuscitation does not occur during this interval. Meanwhile, some centres continue to use an interval of asystole as short as two minutes. Despite the premise of certainty in determining irreversible death, it is worrisome that centres can not agree to adopt a common standard. There are also reports of the use of cardiopulmonary bypass or extracorporeal membrane oxygenation following the required interval of cardiac asystole. ${ }^{44-46}$ As discussed by Arnold and Youngner, "if it requires ten or more minutes without perfusion for the brain to "die," how can its status be ignored after a shorter time? These protocols raise the spectre of a patient experiencing pain or worse, regaining consciousness when cardiopulmonary function (and brain perfusion) are restored by mechanical means such as cardiopulmonary bypass." 39

\section{Time, timing and potential conflict of interest}

Because of the conflict between the interests of dying persons (potential donors), and the interests of potential recipients, it is standard practice that health pro- fessionals responsible for treatment decisions for the still-living patient be separate from the health professionals responsible for subsequent organ recovery and transplant. This separation of roles is in an attempt to ensure that the care of the still-living patient is not compromised by behaviour designed to enhance organ procurement. ${ }^{47}$ Conflict of interest may arise in several circumstances. ${ }^{48}$ For example, if it is determined that active treatment is 'futile' i.e., goals of treatment cannot be met, therapy should be withdrawn. If in this circumstance the patient is eligible as a potential 'controlled' NHBD, the timing of treatment withdrawal (the duration of the dying process) may be influenced by factors related more to concern for recipients than concern for the donor. ${ }^{47}$ Time pressures inherent in NHBD protocols may influence resuscitation personnel to abandon resuscitation efforts or conversely to prolong external cardiac massage and ventilation whilst simultaneously seeking family consent in circumstances where the patient is a potential 'uncontrolled' NHBD. ${ }^{39}$ Finally, individuals within institutions that support NHBD programs may find it difficult to oppose conduct intrinsic to supporting the transplant program, even if this conduct is in conflict with ethical obligations to the donor. ${ }^{49,50}$

Unfortunately, attempts to estimate the frequency of real or perceived conflicts of interest related to NHBD protocols, or the discomfort within members of the health care team are lacking. ${ }^{51,52}$ Despite the separation of the responsible functions of health care professionals involved in the care of potential NHBD and potential recipients of organs from these donors, these separate functions do not necessarily exclude conflicts of interest. As discussed by Shaw, rather than ignoring these conflicts, they should be identified, and discussed openly and fully in the interest of maintaining honesty with the public. ${ }^{48}$

\section{Time, timing, consent and interventions that do not benefit the patient}

Several NHBD protocols permit ante-mortem pharmacologic interventions and/or ante-mortem or postmortem invasive procedures that do not benefit the patient. These interventions may perhaps hasten death, and in particular with postmortem invasive procedures, may be performed with neither family consent, nor the obligation to inform families subsequently that these procedures have been performed.

In most reported OPO controlled NHBD protocols from the USA, consent is obtained from the family prior to ante-mortem placement of vascular catheters, and the catheters are not used until death has been declared. If valid informed consent is 
obtained, this would seem, on balance, to be ethically acceptable. In fact, in some centres, ante-mortem placement has permitted rapid cooling and mitigation of warm ischemic injury following death, and permitted families to grieve at the bedside without having to witness the patient departing to the operating room prior to death.

The principle of 'double-effect' during end-of-life care permits the use of medications, such as morphine, for the specific purpose of relieving pain even though a secondary effect such as respiratory depression may occur which hastens death. Because the primary purpose is the relief of pain to the benefit of the patient, the secondary untoward effect is considered a necessary consequence of the laudable primary purpose..$^{53}$ NHBD protocols commonly use heparin to prevent intravascular clotting in the organs to be recovered, and phentolamine, to maintain vascular perfusion. Neither of these medications can be considered to be used for a primary purpose of benefiting the patient, and either medication may have a negative secondary effect of hastening death. As such, this would seem to be a clear violation of an ethical responsibility to the still alive patient.

Postmortem interventions (such as in situ cold preservation, cardiac massage and mechanical ventilation, and cardiopulmonary bypass) often proceed in the absence of consent. Motivating these procedures is the time constraint and the risk of warm ischemic injury and the loss of potential donor organs. ${ }^{7}$ The rationale behind instituting these interventions is complemented by the reasoning that their use prevents warm ischemia and offers more families the benefit of donating organs. ${ }^{54}$ On the other hand, if families who refuse donation are not informed of the procedures (to protect them from emotional turmoil) principles of honesty and integrity are compromised. ${ }^{2}$ There is a substantial body of literature arguing that the performance of medical procedures (for education) on the recently dead without consent is inappropriate. These authors argue that the principle of respecting the dignity of the recently dead does not justify the unilateral institution of these procedures without consent regardless of the cause. ${ }^{55-60}$ Opponents to NHBD protocols and procedures argue for a moratorium on such practices unless an "overwhelming majority" of the public agrees in principle to these approaches.

\section{Time, timing and the dignity of death}

The need to rapidly retrieve organs to limit warm ischemic time, and the timing of withdrawal of treatment must be reconciled with the need to respect fam- ily grieving. The separation from the family at the time of death has been eschewed as a "desolate, profanely "high-tech death," and death in a controlled NHBD as macabre and ghoulish, an antithesis of quality endof-life care, when health care teams await at the bedside for death and then rapidly procure organs in a race against ischemic time. ${ }^{61}$ The use of ante-mortem catheters to facilitate in situ preservation may mitigate some of these concerns. In many centres this has allowed families to remain at the bedside prior to and during death. The donor is only transferred to the operating room after the family's departure.

\section{Should NHBD protocols be initiated in Canada?}

The death of individuals on transplant waiting lists and the increasing gap between those in need of an organ transplant, and available organs, remain central to initiatives to increase organ donation rates in Canada. The donation and recovery of tissues and organs from individuals that have died, whether from cardiopulmonary or neurological criteria, could reduce the gap. However, the retrieval of organs from NHBD raises many serious ethical concerns that must be addressed prior to commencing NHBD initiatives in Canada.

Arnold and Youngner ${ }^{39}$ first suggested that NHBD protocols require: 1) community ownership as the altruistic concept of organ donation is dependent on community goodwill; and 2) that conflict of interest should be minimized. Therefore the development of NHBD policies should be initiated by individuals exclusive to the transplant community. This does not imply that transplant professionals should be excluded, rather, that they bring their expertise as an equal partner with other health care professionals and members of the public and community. ${ }^{52} 3$ ) Protocols should be developed that provide strict guidance on issues such as determination of death, consent, situations of potential conflict of interest, and program evaluation; and 4) policies should develop as a national consensus, and not simply within single institutions.

In their 1997 report, the Institute of Medicine put forward six principles relevant to all cadaveric donations irrespective of the recovery of tissue or solid organs, and method of the determination of death (Table II). ${ }^{15}$ The authors of the report called for a national policy in the United States as they believed uniformity would potentially engender public confidence, whereas continuing with disparate local policies which simply reflect differences in custom, might be detrimental to the public trust necessary for the entire organ donation-transplantation process. The recommendations of their follow-up report continue to emphasize these important principles (Table III). ${ }^{16}$ 
TABLE II Principles inherent in organ and tissue donation*

1) There is societal value in enhancing organ and tissue donation.

2) Cadaveric donors must be dead at the time of organ or tissue recovery.

3) There must be an absolute prohibition on active euthanasia.

4) There should be complete public openness about policies and protocols

5) There must be a commitment to informed consent.

6) There must be respect for donor and family wishes.

*Based on the Institute of Medicine report. ${ }^{15}$

TABLE III Institute of Medicine ${ }^{15} 1997$ recommendations for a United States National Policy on NHBD

1) Written, locally approved NHBD protocols.

2) Public openness of NHBD protocols.

3) Case by case decisions on anticoagulants and vasodilators.

4) Family consent for premortem cannulation.

5) Conflict of interest safeguards - separate times and personnel for important decisions.

6) Determination of death in controlled NHBD by cessation of cardiopulmonary function for at least five minutes by electrocardiographic and arterial pulse pressure monitoring.

7) Family options (e.g., attendance at life support withdrawal) and financial protection.

NHBD $=$ non-heart-beating organ donors.

However, these recommendations fail to address clearly important issues such as ante-mortem use of medications not in the best interests of the patient, and remain silent on certain issues such as postmortem cannulation, and governance to ensure local compliance with national standards.

\section{Conclusion}

In summary, ethical concerns raised in organ retrieval from NHBD, include: 1 ) the determination and timing of death; 2) real or perceived conflicts of interests for health care providers and institutions; 3 ) interventions performed to the potential harm of the still alive donor solely for the benefit of the future organ recipient; and 4) the loss of the dignity of the dying process.

In a recent position paper, the Canadian Critical Care Society called for a moratorium on instituting local NHBD protocols in Canadian centres. ${ }^{62} \mathrm{We}$ believe a moratorium should continue until at least a Canadian national consensus emerges, with reflection and resolution of contentious issues considerate of Canadian values and with the input of the Canadian public. Several strategies, including NHBD protocols, have the potential to increase organ and tissue dona- tion rates in Canada. They should all be based on sound ethical and legal principles, and not just on the need to match 'supply' with 'demand'.

\section{References}

1 Evans R, Orians CE, Ascher NL. The potential supply of organ donors. An assessment of the efficiency of organ procurement efforts in the United States. JAMA 1992; 267: 239-46.

2 Youngner SJ, Arnold RM. Ethical, psychosocial, and public policy implications of procuring organs from non-heart-beating cadaver donors. JAMA 1993; 269: 2769-74.

3 Edwards JM, Hasz RD Jr, Robertson VM. Non-heartbeating organ donation: process and review. AACN Clin Issues 1999; 10: 293-300.

4 DeVita MA, Snyder JV, Grenvik A. History of organ donation by patients with cardiac death. Kennedy Inst Ethics J 1993; 3: 113-29.

5 Lock $M$. Twice dead. Organ transplants and the reinvention of death. In: Borofsky $\mathrm{R}$ (Ed.). California Series in Public Anthropology. Berkeley: University of California Press; 2002: 429.

6 Morioka M. Reconsidering brain death: a lesson from Japan's fifteen years of experience. Hastings Cent Rep 2001; 31: 41-6.

7 Anaise D, Rapaport FT. Use of non-heart-beating cadaver donors in clinical organ transplantation logistics, ethics, and legal considerations. Transplant Proc 1993; 25 : 2153-5.

8 Ferriman $A$. Spain tops the table for organ donation. BMJ 2000; 321: 1098.

9 Baxter D. The Urban Futures Institute Report 51. Beyond Comparison: Canada's Organ Donation Rates in an International Context. Vancouver: The Urban Futures Institute; 2001.

10 Baxter D. The Urban Futures Institute Report 48. A Decade of Donation: Measurement of Organ Donation Rates in Canada 1988-1997. Vancouver: The Urban Futures Institute; 2000.

11 Baxter D, Smerden J. The Urban Futures Institute Report 46. Donation Matters: Demographics and Organ Transplantation in Canada, 2000 to 2040. Vancouver: The Urban Futures Institute; 2000.

12 Koostra G. Statement on non-heart-beating donor programs. Transplant Proc 1995; 27: 2965.

13 Koostra G, Kievit JK, Heineman E. The non heartbeating donor. Br Med Bull 1997; 53: 844-53.

14 Anonymous. University of Pittsburgh Medical Center Policy and Procedure Manual. Kennedy Inst Ethics J 1993; 3: Al-15.

15 Institute of Medicine. Non-Heart-Beating Organ Transplantation: Medical and Ethical Issues in 
Procurement. Washington DC: National Academy Press; 1997.

16 Institute of Medicine. Non-Heart-Beating Organ Transplantation: Practices and Protocols. Washington DC: Institute of Medicine National Academy Press; 2000.

17 Koostra G. The asystolic, or non-heartbeating, donor. Transplantation 1997; 63: 917-21.

18 Steen S, Sjoberg T, Pierre L, Liao Q Eriksson L, Algotsson L. Transplantation of lungs from a non-heartbeating donor. Lancet 2001; 357: 825-9.

19 Anaise D, Smith R, Ishimaru M, et al. An approach to organ salvage from non-heartbeating cadaver donors under existing legal and ethical requirements for transplantation. Transplantation 1990; 49: 290-4.

20 Light J. A 25 year history of kidney transplantation at the Washington Hospital Center. Clin Transpl 1998; 159-68.

21 Clayton HA, Swift SM, Turner JM, James RF, Bell PR. Non-heart-beating organ donors. A potential source of islets for transplantation? Transplantation 2000; 69: 2094-8.

22 Casavilla A, Ramirez C, Shapiro R, et al. Liver and kidney transplantation from non-heart beating donors: the Pittsburgh experience. Transplant Proc 1995; 27: 710-2.

23 D'Alessandro AM, Hoffman RM, Knechtle SJ, et al. Successful extrarenal transplantation from non-heart beating donors. Transplantation 1995; 59: 977-82.

24 D'Alessandro AM, Hoffman RM, Knechtle SJ, et al. Liver transplantation from controlled non-heart-beating donors. Surgery 2000; 128: 579-88.

25 Gomez M, Garcia-Buitron JM, Fernandez-Garcia A, et al. Liver transplantation with organs from non-heartbeating donors. Transplant Proc 1997; 29: 3478-9.

26 Rilo HL, Carroll PB, Trucco M, et al. Human pancreatic islet isolation from a diabetic non-heart-beating donor. Transplant Proc 1994; 26: 598.

27 Tojimbara T, Teraoka S, Babazono T, et al. Long-term outcome after combined pancreas and kidney transplantation from non-heart-beating cadaver donors. Transplant Proc 1998; 30: 3793-4.

28 Mauney MC, Cope JT, Binns OA, et al. Non-heartbeating donors: a model of thoracic allograft injury. Ann Thorac Surg 1996; 62: 54-62.

29 Martin J, Sarai K, Yoshitake M, et al. Orthotopic transplantation of pig hearts harvested from non-heart-beating donors. Transplant Proc 1999; 31: 153-4.

30 Martin J, Sarai K, Yoshitake M, et al. Successful orthotopic pig heart transplantation from non-heart-beating donors. J Heart Lung Transplant 1999; 18: 597-606.

31 Campbell G, Sutherland FR. Non-heart-beating organ donors as a source of kidneys for transplantation: a chart review. CMAJ 1999; 160: 1573-6.

32 Cecka JM. Donors without a heartbeat (Editorial). New Engl J Med 2002; 347: 281-3.

33 DuBois JM. Ethical assessments of brain death and organ procurement policies: a survey of transplant personnel in the United States. J Transpl Coord 1999; 9: 210-8.

34 Agich GJ. From Pittsburgh to Cleveland: NHBD controversies and bioethics. Camb Q Healthc Ethics 1999; 8: 269-74.

35 Robertson JA. The dead donor rule. Hastings Cent Rep 1999; 29: 6-14.

36 Arnold RM, Youngner SJ. The dead donor rule: should we stretch it, bend it, or abandon it? Kennedy Inst Ethics J 1993; 3: 263-78.

37 Bos $M A$. Legal issues concerning the use of non-heartbeating donors. Transplant Proc 1995; 27: 2929-32.

38 Ad Hoc Committee of the Harvard Medical School to examine the definition of brain death. A definition of irreversible coma. JAMA 1968; 205: 337-40.

39 Arnold RM, Youngner SJ. Time is of the essence: the pressing need for comprehensive non-heart-beating cadaveric donation policies. Transplant Proc 1995; 27: 2913-21.

40 Lynn J. Are the patients who become organ donors under the Pittsburgh protocol for "non-heart-beating donors" really dead? Kennedy Inst Ethics J 1993; 3 : 167-78.

41 Tomlinson $T$. The irreversibility of death: reply to Cole. Kennedy Inst Ethics J 1993; 3: 157-65.

42 Cole D. Statutory definitions of death and the management of terminally ill patients who may become organ donors after death. Kennedy Inst Ethics J 1993; 3: 145-55.

43 Menikoff J. Doubts about death: the silence of the Institute of Medicine. J Law Med Ethics 1998; 26: 157-65.

44 Koyama I, Shinozuka N, Watanabe T, et al. Utilization of kidneys from non-heart-beating donors by portable cardiopulmonary bypass. Transplant Proc 1997; 29: 3550-1.

45 Koyama I, Hoshino T, Nagashima N, Adachi K, Ueda $K$, Omoto $R$. A new approach to kidney procurement from non-heart-beating donors: core cooling on cardiopulmonary bypass. Transplant Proc 1989; 21: 1203-5.

46 Ko WJ, Chen YS, Tsai PR, Lee PH. Extracorporeal membrane oxygenation support of donor abdominal organs in non-heart-beating donors. Clin Transpl 2000; 14: 152-6.

47 Guest CB, Devitt JH. Non-heart-beating organ donation (Letter). CMAJ 2000; 162: 194.

48 Shaw BW Jr. Conflict of interest in the procurement of 
organs from cadavers following withdrawal of life support. Kennedy Inst Ethics J 1993; 3: 179-87.

49 Frader J. Non-heart-beating organ donation: personal and institutional conflicts of interest. Kennedy Inst Ethics J 1993; 3: 189-98.

50 Burdick JF. Potential conflicts of interest generated by the use of non-hear-beating cadavers. Kennedy Inst Ethics J 1993; 3: 199-202.

51 Robertson JA. Policy issues in a non-heart-beating donor protocol. Kennedy Inst Ethics J 1993; 3: 241-50.

52 Caplan AL. The telltale heart: public policy and the utilization of non-heart-beating donors. Kennedy Inst Ethics J 1993; 3: 251-62.

53 Hawryluck LA, Harvey WR. Analgesia, virtue, and the principle of double effect. J Pall Care 2000; 16(Suppl): S24-30.

54 Barber SD. The tell-tale heart: ethical and legal implications of in situ organ preservation in the non-heartbeating cadaver donor. Health Matrix Clevel 1996; 6: 471-502.

55 Orlowski JP, Kanoti GA, Mehlman MJ. The ethics of using newly dead patients for teaching and practicing intubation techniques. New Engl J Med 1988; 319: 439-41.

56 Stryker J. Practicing intubation on the newly dead (Letter). N Engl J Med 1989; 320: 396.

57 Culver C. Commentary: using a cadaver to practice and teach. Hastings Cent Rep 1986; 16: 28-9.

58 Denny CJ, Kollek D. Practicing procedures on the recently dead. J Emerg Med 1999; 17: 949-52.

59 Alden AW, Ward KL, Moore GP. Should postmortem procedures be practiced on recently deceased patients? A survey of relatives' attitudes. Acad Emerg Med 1999; 6: 749-52.

60 Manifold CA, Storrow A, Rodgers K. Patient and family attitudes regarding the practice of procedures on the newly deceased. Acad Emerg Med 1999; 6: 110-5.

61 Fox RC. "An ignoble form of cannibalism": reflections on the Pittsburgh protocol for procuring organs from non-heart-beating cadavers. Kennedy Inst Ethics J 1993; 3: 231-9.

62 Rocker GM, for the Canadian Critical Care Society Working Group on Organ and Tissue Donation. Organ and tissue donation in the intensive care unit. CMAJ 2002; 167: 1248-9. 